\title{
DEVELOPING CRITICAL READING, THINKING AND DISCUSSION SKILLS AMONG STUDENTS AT A MASTERS LEVEL USING VIRTUAL LEARNING ENVIRONMENT
}

\author{
Yekatherina Bobrova*1, Ljiljana Marjanovic- Halburd ${ }^{1}$, Peter McLennan ${ }^{1}$ \\ ${ }^{1}$ UCL Institute for Environmental Design and Engineering, The Bartlett School of \\ Environment Energy and Resources, University College London (UK) \\ *corresponding author (yekatherina.bobrova.12@ucl.ac.uk)
}

\begin{abstract}
Students entering higher education at Masters level often struggle to develop skills of critical reading, discussion and analysis. That lack of skills often affects the quality of students' written coursework, even if such work shows an extensive knowledge and understanding of the topic. Academic literature suggests that skills, including cognitive ones, are best developed by going through a learning cycle several, if not many, times. Feedback on students' activities is known to help students to go through a learning cycle quicker. However, the feedback itself needs to be understood by the students, which could only happen if they possess knowledge of fundamental principles underpinning the coursework. The main objective of this study is to introduce a feedforward learning activity that would familiarise postgraduate students with core concepts of critical reading, discussion and writing skills. Such understanding is expected to increase students' performance in their subsequent written work. The proposed feedforward activity took a form of Generic Quizzes embedded in e-learning environment. The success of the quizzes was tested in two cohorts undertaking the same Masters programme. The results suggested that such Quizzes are capable of accelerating students' familiarisation with core principles of critical thinking and analysis, which results in substantial improvement of their subsequent written coursework. However, that process only occurred when given feedback was understood by the students, which only happened is a discussion of the learning activity with a module tutor. Therefore, even though the amount of teaching resources needed for a continuous support of the proposed learning activity is substantially reduced compared to a usual form of student-tutor interaction such as a seminar, it could not be completely eliminated.
\end{abstract}

Keywords: Critical analysis, postgraduate taught education, skills development, repetition, Virtual Learning Environment.

\section{BACKGROUND}

\subsection{Motivation}

Students entering higher education at Masters level often struggle to develop skills of critical reading, discussion and analysis. That lack of skills can then potentially negatively affect the quality of students' written coursework, even if such work shows an extensive knowledge and understanding of the topic. Academic literature suggests that skills, including cognitive ones, are best developed by repetition. However, even though graduate programs usually offer students lectures and tutorials on critical thinking and analysis, they often lack teaching capacity to repeat those activities until a desired level of students' skills is achieved.

\subsection{Theoretical position}

\subsubsection{Learning Cycle}

In this paper a theoretical learning framework introduced by Kolb [1] is used guide the design of the study. In his work Kolb suggests that learning occurs in cycles, and in order to consolidate the knowledge gained one needs to go around the circle one, if not many, times. As seen on Fig. 1 Kolb suggests four stages in a learning cycle: observing new information and reflecting on previous experience; generalising based on the observations made and forming new concepts of understanding; planning how to do things based on newly achieved understanding; and finally implementing a newly obtained understanding in practice by 'doing it'. 


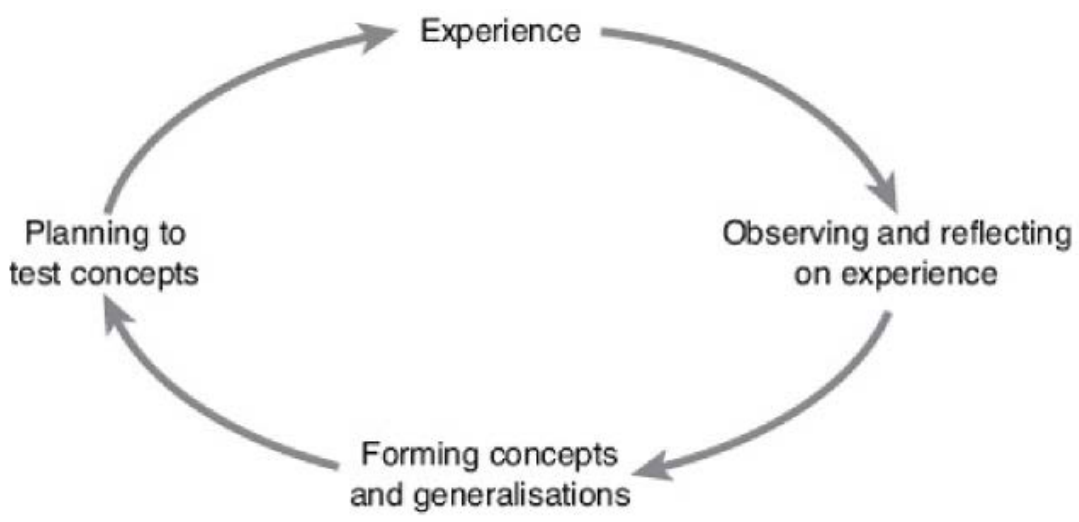

Fig 1. Experiential learning cycle from Kolb, 1984 [1]

Kolb's model not only highlighted an iterative process of learning, but also stressed an importance of developing a skill of applying newly gained knowledge by 'doing it' and afterward reflecting on the experience - an aspect often overlooked in higher education [2].

\subsubsection{Feedback}

As suggested by Kolb's learning cycle, knowledge is obtained through a process of reflection on one's experience [1]. In higher education that process of reflection is directed and supported by feedback given by tutors on students' work, thus accelerating the process of learning [3]. Indeed, many studies suggest that feedback is central to development of effective learning experience among postgraduate students [2, 3]. Nevertheless, in his study Sadler [3] suggests that even though students appreciate such feedback, it often leads to little or no improvement of subsequent work. Sadler argues that students need some fundamental working knowledge in relevant concepts in order to convert such feedback into action. In higher education tutors tend to compose their feedback on a particular assignment based on their fundamental knowledge of what a research work should be. However, students might lack that fundamental understanding, preventing them from getting the most of the feedback given. Sadler [3] suggest that it is crucial to familiarise students with the concepts, based on which their future work will be assessed, so they could understand and benefit from a future feedback later on. That type of communication is often referred to as 'feedforward' as it is future oriented [4].

An overall aim of that feedforward activity is making students understand the reasons behind the quality assessment of their work given in a form of a feedback, and in the process of achieving that understanding developing personal capability to make comprehensive appraisal of their work, ultimately empowering them to become self-regulated learners [5].

In summary, in order to ensure effective learning experience, curriculum design needs to ensure sufficient opportunities for students to familiarise themselves with core concepts, based on which their subsequent work will be judged; a timetable that permits feedback on an understanding of such concepts, which feeds forward into next assignment; and students learning from this [3, 6].

\subsection{Objectives}

The main objective of this study is to introduce a feedforward learning activity that would familiarise postgraduate students with core concepts of critical reading, discussion and writing skills. Such understanding is expected to increase students' performance in their subsequent written work.

Another objective of the study is to ensure that minimum teaching resources are required to support such activity.

\subsection{Description of the study}

\subsubsection{Feedforward learning activity}

The proposed feedforward activity took a form of a Generic Quiz, aimed to familiarise students with core principles of what a research work is expected to look like. The Generic Quiz comprised of six sections typical to be found in a written academic work such as a journal paper or a dissertation: a purpose of the study, a literature review, objectives of the study, research methodology, results and discussion, and conclusions. Each section had three questions - one multiple-choice question and two open questions. A multiple-choice question represented a choice between 5 possible marks: 
80\%+ Exceptional, 70-80\% Excellent work, 60-69\% Very good, 50-59\% Satisfactory, 49\% and less Fail. Each choice was accomplished with a short generic description relevant to an appropriate section of the Generic Quiz. For instance, the mark 70-80\% Excellent work for the methodology section was accomplished by the following generic description: "Strong methodology that is supported by literature is clearly developed and effectively applied to the problem stated". In open questions students were asked to summarise their understanding of a section (e.g. a methodology section) and give their critical reflection on it.

The students were asked to evaluate several academic and non-academic articles using those Generic Quizzes by giving grades on each section (e.g. a methodology chapter of an article), providing a short summary of that section and giving a short critical reflection on it. After submitting their quizzes, the students were given grades and answers on the same articles provided by one of their tutors.

Initial familiarisation with core concepts of critical thinking, reading and writing was expected to occur during students' familiarisation with generic answers provided in multiple choice questions. The students would then proceed to form their understanding of those concepts and applying that understanding immediately by evaluating an academic article via the Generic Quiz. Answers provided by tutors were expected to act as a feedback mechanism, prompting a reflection on an undertaken activity.

\subsubsection{E-learning environment}

In order to reduce an amount of teaching resources needed to support the learning activity, the General Quizzes were embedded in a Virtual Learning Environment. That arrangement allowed the tutors to set up the activity only once rather then each time, it allowed students to finish the activity in their own time an pace, as well as to received immediate feedback on the completion.

\section{METHODOLOGY}

The effectiveness of the developed on-line Quizzes was tested on two sets of participantspostgraduate students undertaking the same MSc course delivered by face-to-face teaching at two locations: London and Singapore. In London the course is delivered via traditional classroom based teaching, in Singapore - via blended learning.

\subsubsection{London Cohort}

In London two Generic Quizzes were introduced in a core FE1 module. The module was delivered in Term 1 with weekly seminars.

Three papers were chosen for evaluation. Tutors evaluated the papers as following: L1 paper received high grades (60s and 70s) throughout all sections. The only exception was a conclusion section, which was gradated as 50s. L2 and L3 papers were on the same topic from different perspectives. They were gradated very similar by the tutors, both receiving grades ranging from 40 s to 70 s across different sections, showing inconsistency in the strength of different sections.

L1 paper was introduced first in the module around October. The associated Generic Quiz was split in 3 with 2 sections in each Quiz. L2 and L3 paper were introduced simultaneously at the end of the module around early December. The associated Generic Quizzes came in one block of six sections.

A discussion on the results of the quizzes as well as a discrepancy between marks given by students and the ones given by tutors were held after each quiz, which allowed students to receive further feedback on the knowledge they were gaining. A feedback from the students regarding the quizzes was collected twice prior the end of the module. A feedback was also given to the students prior the end of the module on the expectations of the effect of the learning activity on their final written submission.

The completion of the quizzes was voluntarily.

\subsubsection{Singapore Cohort}

In Singapore two Generic Quizzes were introduced in an elective FES module. The module was delivered as a block over 3,5 days mid Term 1.

Two papers were chosen for evaluation. S1 paper were graded quite poorly by the tutors with most of the sections receiving 40 s and 50 s. S2 paper received more favourable grades, most of them ranging 
around 60s.

Both papers were introduced at the same time at the end of the module around early December. The associated Generic Quizzes came in one block of six sections.

Although the idea of the Quizzes was introduced to the students during the block teaching and their implementation within e-leaning environment was demonstrated, there was no further discussion of the Quizzes and their results with the students. A feedback exchange from the students and to them was only held after the end of the module, and thus after the submission of the final assignment.

The completion of the quizzes was mandatory. In order to avoid over-assessment [6] and create 'fearfree' environment [7] students were not marked on the Quizzes. They had, however, to complete the Quizzes in order to submit their final written assessment.

\subsubsection{Criteria to evaluate success of the learning activity}

The success of the proposed approach was judged based on the following criteria:

- students' performance in their first written submission (both cohorts have the same summative assignment assessment $-2,500$ word essay) at the end of the semester compared with performance on the same submission showed in the previous year;

- improvement of individual students' skills, based on the improvement of their answers in each successive quiz as compared to tutors' answers;

- a feedback about those quizzes received from the students;

- amount of teaching resources required to support the quizzes.

\section{RESULTS}

\subsubsection{Students' performance in their final written submission vs performance in Generic Quizzes}

Students' performance of the 2015/16 London cohort was compared to the performance of the 2014/15 London cohort. Due to the nature of Singapore delivery, where all students are part-time professionals, the FES module is delivered every two years, therefore the 2015/16 cohort was compared with 2013/14 one. A comparison of students' performance in their final written submission with the performance of the students from previous years implies that such comparison is justified, as initial level of students across different years is uniform. It is indeed true for the London cohort, as students held similar grades for their undergraduate degrees in both 2015/16 and 2014/15 years. However, the initial level of the Singapore cohort was different. 10\% of the cohort in Singapore 2 years ago had 1st at undergraduate level, and further $20 \%$ had 2:1. This years FES cohort all entered the programmes with $2: 2 \mathrm{~s}$. In both cohorts there were few students who did not have the undegraduate degree but were allowed on the programme anyway.

As seen in Table 1. in comparison to the previous year, students' average mark in the London cohort in their final written submission has increased from 'good' to 'very good'; the spread of marks within the cohort was narrower; the spread of marks between a first and a second marker was substantially reduced. Another interesting observation could be noted from Table 1: a second marker tend to give a lower grade to a student, as he probably more likely to be less familiar with a student, and therefore more likely to give more objective marks based on students' actual performance, rather then their potential. Therefore, a reduction in a spread of marks between a first and a second marker suggests that students were more likely to have produced work consistent with academic expectations in 2015/16 year rather then in 2014/15 year.

However, that picture is not replicated in the Singapore cohort, in which an average mark in the final written submission has actually reduced, and the spread of those marks has increased.

Table 1. Students' marks in their final written submission

\begin{tabular}{|l|l|l|l|l|}
\hline & \multicolumn{2}{|c|}{ London (FE1) } & \multicolumn{2}{c|}{ Singapore (FES) } \\
Cohort size (received a pass mark) & $2015 / 16$ & $2014 / 15$ & $2015 / 16$ & $2013 / 14$ \\
Av. mark for final submission (st. d.) & 7 & 17 & 10 & 34 \\
Av. mark difference 1st vs 2nd marker (st.d.) & $66(1.8)$ & $63(5.1)$ & $57(9)$ & $61(12.9)$ \\
\hline
\end{tabular}


In the rest of the section the differences between London and Singapore cohort, as well as the differences between their participation and performance in Generic Quizzes will be examined, in order to shed some light on the differences in their performance in the final written submission.

Students from both cohorts only did two Quizzes. The students from the London cohort were given three quizzes, the last two of which were on very similar papers, that were then discussed in class on the same day. All the students chose to do a Quiz for one of those papers only.

Table 2 gives a summary of the Generic Quizzes as well as results for the final written submission for the London cohort. Table 3 gives corresponding results for the Singapore cohort. The results for the Quizzes show a discrepancy between the marks given by a student and the marks given by a tutor on the same section of a Quiz. The tables also include completion time as well as a timeline with some notable days, such as the days for discussion of the Quizzes and a due day for the final written submission.

Table 2. Students marks in their final written submission and Generic Quizzes. London cohort (a Generic Quiz has a choice of 5 marks: 40s, 50s, 60s, 70s and 80s. If a student and a tutor gave the same mark to a section of an article, the discrepancy in their answers is 0 . If a student gave 60s and a tutor - 70s, the discrepancy is 1. If the student gave 70s and a tutor - 50s, the discrepancy is - 2)

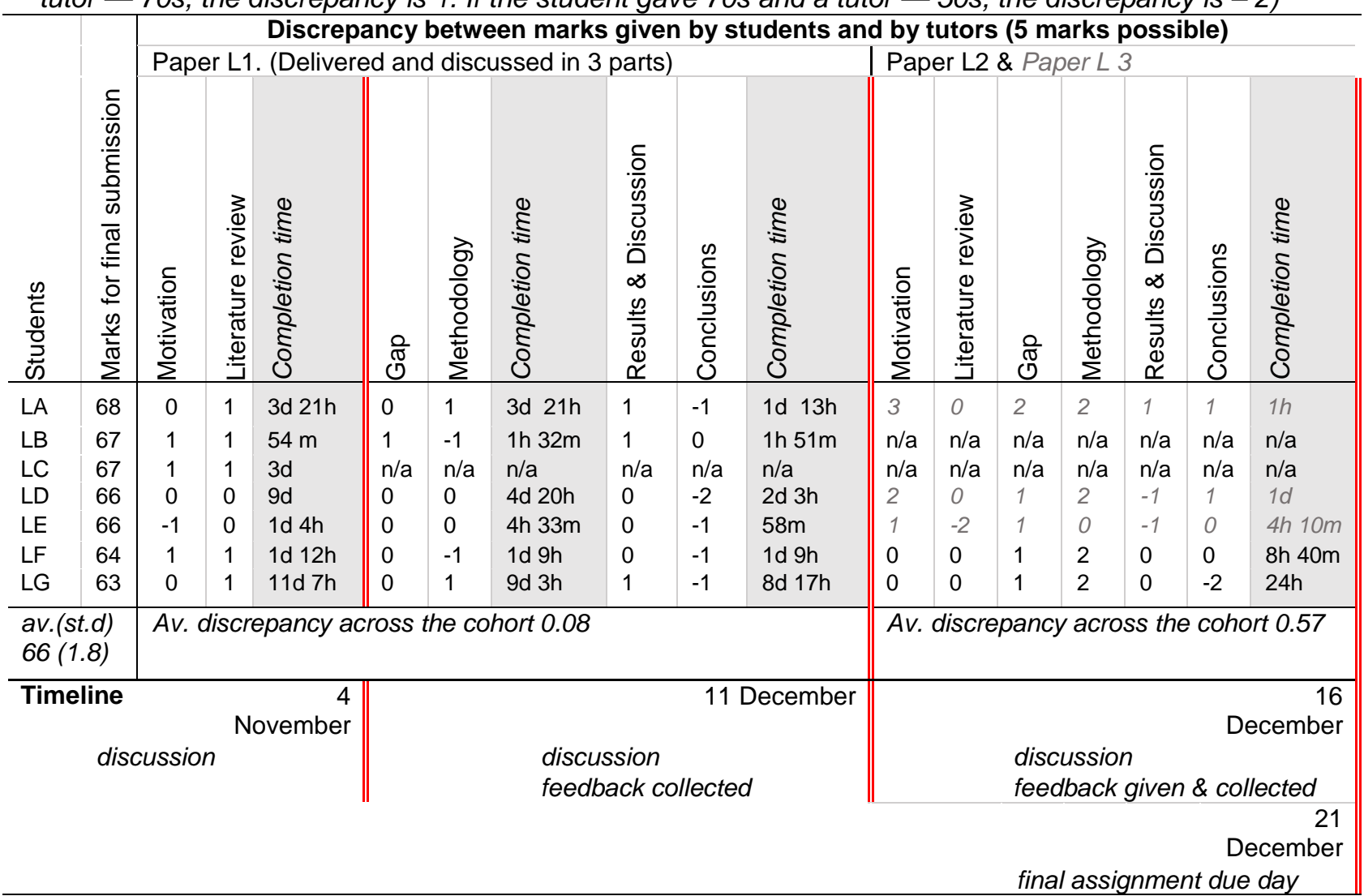

As seen from the tables, students from the London cohort spent significantly more time, often days, filling in the Quizzes. They also spent significantly more time on the first Quiz, which was delivered and discussed in 3 parts. The students from the Singapore cohort tended to spend no more then a couple of hours on each Quiz, sometimes even a few minutes only. However, the student who performed the best in the final written submission in the Singapore cohort also spent the most time on the Quizzes - several days on the first one, and several hours on the second one.

The students from the London cohort had several points of discussion regarding the Quizzes and the answers given by the tutors. They were also given a feedback on the expectations of an effect of the Quizzes on the quality of their final written assignments. All of that happened over a span of a few months before the final assignment due day, possibly giving the students more time for reflection. The students from the Singapore cohort were not involved in discussions regarding the Quizzes and the 
results. The feedback was also only collected and given to them after the submission of their final written work.

The students from the Singapore cohort also showed a much higher deviation in their marks from the marks of the tutors when compared to the London cohort, suggesting a lower initial level of understanding of the principles of critical analysis in the Singapore cohort.

Table 3. Students marks in their final written submission and Generic Quizzes. Singapore cohort (a Generic Quiz has a choice of 5 marks: 40s, 50s, 60s, 70s and 80s. If a student and a tutor gave the same mark to a section of an article, the discrepancy in their answers is 0 . If a student gave 60s and a tutor - 70s, the discrepancy is 1. If the student gave 70s and a tutor - 50s, the discrepancy is - 2)

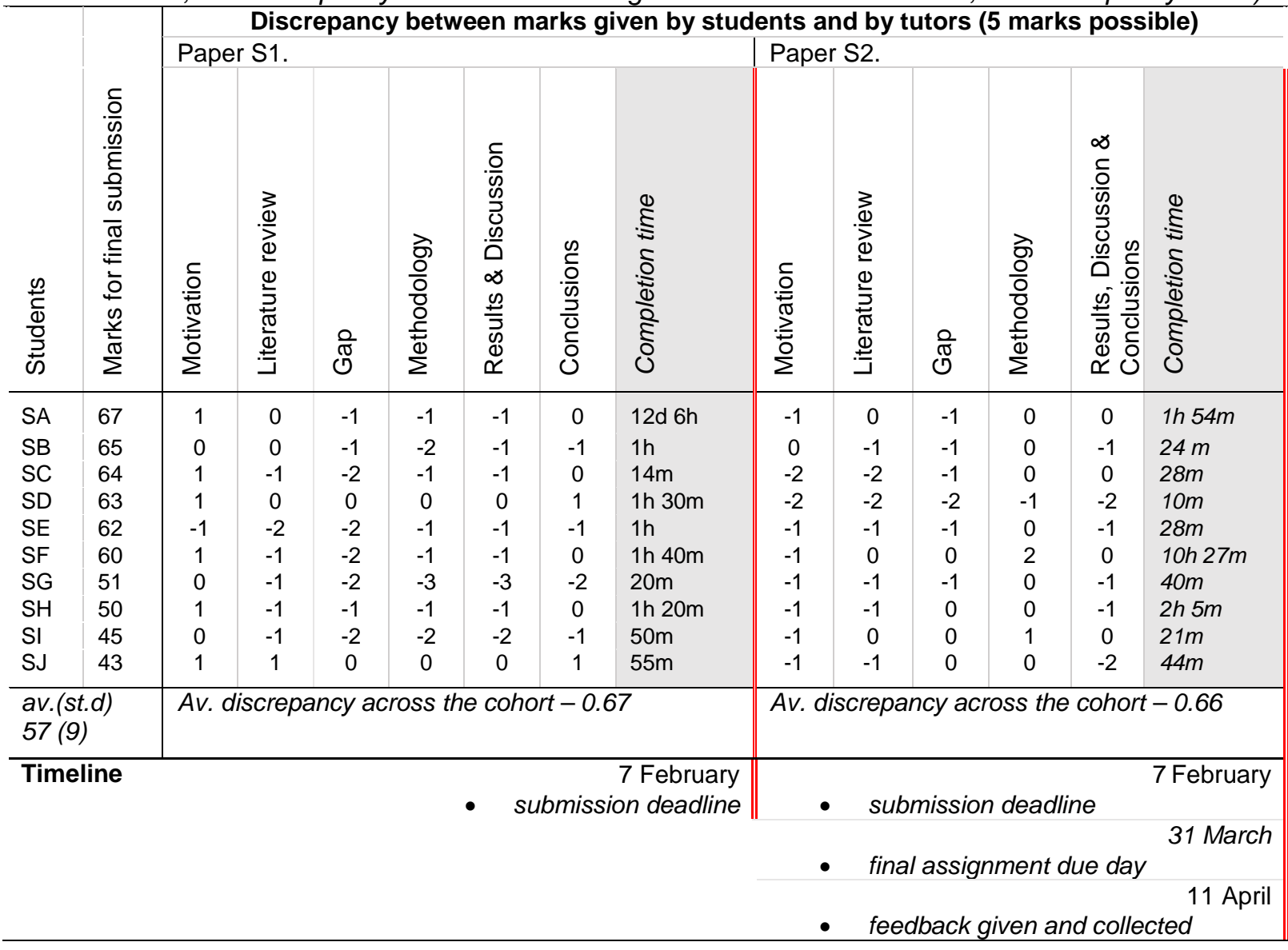

An interesting observation could be made from the data, which might suggest some cultural differences. The students from the Singapore cohort tended to grade the articles more favourably then the tutors, whereas the students from the London cohort tended to be stricter then the tutors.

\subsubsection{Improvement of students' individual critical skills}

As stated earlier, all the sections in the first paper in the London cohort L1 were graded high by the tutors except of the last section - Conclusions. Most of the students gave higher marks to that sections, suggesting lack of critical reading skills at that moment. However, by the time of the second Quiz, the discrepancy in the marks has shifted and students tended to be stricter then the tutors, which is consistent with an overall trend displayed by the London cohort.

The following quotes from the answers given to open questions highlight a learning curve that happened in one of the students in London cohort - a student LA, who also got the highest mark in the final written submission.

LA student comments on a conclusion section of the $1^{\text {st }}$ paper $-\mathrm{L} 1$ :

The conclusions I believe are correct from the data which has been collected and processed. 
LA student comments on a conclusion section of the $2^{\text {nd }}$ paper - L3:

The conclusions are very generic and due to the lack of rigour in the methodology and literature review there overall relevance of conclusions are difficult to judge.

The comments highlight a journey from an understanding of conclusions as being correct or incorrect, to understanding of them as an integral part of an article, underpinned by a methodology and a literature review.

\subsubsection{Feedback from the students}

Feedback from both cohorts was gathered in person before a beginning of a scheduled lecture. The students were not informed about the feedback collection beforehand. In London the module tutor was present during the feedback collection, in Singapore the module tutor was absent. The feedback was collected by a Teaching Assistant, who was not directly involved in neither modules. The feedback was collected in a form of an open discussion. Literature suggests that such feedback collection design might have a problem of anonymity [3] biasing the results. However, it was decided to proceed in that way in order to gain more fruitful insights.

The London cohort reported that the feedfroward learning exercise with Quizzes helped them to start reading critically academic papers, and helped them shaped their expectations of what a good academic paper should look like and why. They reported that the exercise helped them to develop quickly their critical position and thinking about a paper in particular and a topic in general. Some students that were outside of academia for an extended period of time additionally stressed a usefulness of such activity to get quickly back to thinking 'academically'. The students were later asked if they felt that such exercise helped them thinking about the structure and form expectations of what their final written submission should look like. The students, however, did not see an immediate relation between the two. The Teaching Assistant nevertheless explained them the relation and they understood the rationale. That conversation happened a week before the submission of the final written coursework, giving the students some time to restructure their work.

The Singapore cohort was much less enthusiastic or understanding about the activity. They did not seem to understand the purpose of an exercise and were suggesting that the questions should be much more specific to a paper, as they were not sure what they were looking for. They thought they were asked to find answers in a particular paper rather then develop critical reading skills. The Teaching Assistant explained them the expectation of the exercise, but it was not clear whether they understood it fully. The students, however, reported, that the Quizzes helped them to understand in a structured way what to look for in a paper.

The Singapore cohort students also reported a time-consuming nature of an exercise. They reported that in order to do an exercise properly they would have needed to spend a full day, which they did not feel motivated to do. The students also reported that they lost concentration after first two sections of the first Quiz. They were not enthusiastic about repeating an exercise as they probably did not understand a usefulness of it. They suggested that next time such Quizzes should be scheduled better as deadlines for the current Quizzes were around Chinese New Year. They also asked if more preparatory work could be done in advance to prepare them for an exercise.

\subsubsection{Amount of teaching resources required}

The exercise required substantial initial teaching resources, however the amount of teaching resources needed for a continuous support of the quizzes was reduced to a minimum. In the Singapore cohort the amount of continuous teaching resources was zero, whereas in the London cohort the module tutor spent around 20 minutes 3 times to discuss the Quizzes.

\section{DISCUSSION}

\subsubsection{Initial understanding of fundamental concepts of critical thinking among students}

Research has suggested [2] that it is much more fruitful to build new knowledge based on already existing understandings and concepts. Nevertheless, in this experiment the concept of critical thinking and analysis were introduced as a new idea, probably slowing down the process of students' familiarisation with those concepts. Moreover, those new concepts were only introduced via familiarisation with a grading scheme. In both cohorts formal lectures on research and methods in 
academia were held only at the end of the second term (the described feedforward activity took place the first term).

Moreover, the aims of the exercise were not clearly articulated, or at least, during the feedback collection both cohorts did not correlate those Quizzes with the quality of their written submissions.

\subsubsection{Learning cycle}

The results suggest that even though both cohorts were introduced to a similar learning activity, the Singapore cohort did not have an opportunity to go around Kolb's experiential cycle at all, and therefore desired critical skills remained undeveloped. The London cohort, on the other hand, had a chance to go through the learning cycle several times before the final coursework submission. That discrepancy could explain the difference in performance among two cohorts.

\subsubsection{Feedback}

The Singapore cohort only got an automotive feedback in a form of tutors' answers to the Quizzes, whereas the London cohort also got feedback from the module tutor several times, which seemed to have a positive effect on their grades.

As one of the objectives of the study was to reduce the amount of teaching resources needed to support the activity, other forms of feedback could be considered for future research. Peer review might be one of them, which could enhance collaborative learning and supportive atmosphere.

As Biggs and Tang [7] suggest a successful formative feedback should be an interactive two-way process. At this moment the students did not have much influence on the design of the activity. A strategy for such feedback could be implemented in future work.

\subsubsection{Motivation}

The students from the Singapore cohort were not enthusiastic about repeating the activity again. The students from the London cohort displayed less and less enthusiasm with time: all the students did the first part of the first Quiz, however, one of the students did not finish all six sections and two students did the first Quiz only, opting not to participate in a second one. None of the students did all three Quizzes. It looks like the students' motivation to continue to engage in the activity deteriorated with time.

Indeed, Kolb's learning cycle is often criticised for lacking motivation to learn as an essential element of successful learning [2]. Research shows that motivation is a power driver for learning [8]. Another circular model of learning developed by Race [9] puts motivation in the centre of the learning cycle. The expectancy-value theory of motivation developed by Feather [10] suggest that a learner will only engage in an activity, which he or she both expects to succeed in and values the outcome of. It could be reasonably assumed that the students do not think they might not succeed in the proposed forward learning activity. However, the results showed that the students do not fully understand the value of the task and do not understand a full potential of outcomes. Biggs and Tang [7] classify motivation in four types: extrinsic, when students engage in an activity because they value the outcomes of it; social, when students engage in an activity under social pressure or as part of proactive social activity [11]; achievement motivation, when students engage in an activity as an opportunity for ego enhancement; and intrinsic motivation, when students are involved in an activity because they like the process of doing it. Intrinsic motivation is ideal but difficult to achieve. Achievement motivation is not favourable in a context of collaborative learning. Extrinsic motivation does not seem to work as students do not fully understand the value of the learning activity. Moreover, research suggests that the quality of learning is low under this type of motivation [7], and students are more likely to adopt surface approach to learning under extrinsic motivation [12]. Social motivation seems to have the highest potential for future exploration. Biggs and Tang [7] suggest different types of social learning activities such as peer tutoring and small group learning, which could be embedded into e-learning environment via Knowledge Forum.

\subsubsection{Teaching resources}

The study revealed that proposed quizzes activity require a substantial initial investment of teaching resources, which could be potentially a barrier for that method to be widely implemented. The study also revealed that ongoing teaching support could not be eliminated altogether at least in the beginning until students become self-regulated learners. Nevertheless, social learning such as 
discussions among peer groups could reduce the amount of resources needed to support such feedforward activity.

\section{CONCLUSIONS}

In the current study a feedforrward learning activity was introduced, aiming to develop critical reading, thinking and writing skills among postgraduate students. An activity took a form of Generic Quizzes, the repetition of which was expected to accelerate students' journey along the learning cycle. The study, however, revealed that a quality a feedback has a substantial influence on whether such learning will occur.

The study revealed a value of a proposed activity in developing students' skills of critical reading, discussion and analysis. Some limitations were also revealed, such as a need for substantial initial teaching resources. A future research could replicate the study on a bigger cohort; conduct a longitudinal study; look into introducing more Quizzes within the module, allowing for more repetition to take place; and redesign the activity to keep students motivated for a longer period of time.

\section{REFERENCES}

[1] Kolb, D.A. (1984) Experiential Learning: Experience as the Source of Learning and Development, Prentice-Hall: Englewood Cliffs, N.J.

[2] Morss, K., Murray, R. (2005) Teaching at University: A Guide for Postgraduates and Researchers, SAGE Publications: London.

[3] Sadler, D.R. (2010) 'Beyond feedback: developing student capability in complex appraisal', Assessment \& Evaluation in Higher Education, 35(5), 535-550.

[4] Björkman, M. (1972) 'FEEDFORWARD AND FEEDBACK AS DETERMINERS OF KNOWLEDGE AND POLICY: NOTES ON A NEGLECTED ISSUE', Scandinavian Journal of Psychology, 13(1), 152-158.

[5] Carless, D. (2006) 'Differing perceptions in the feedback process', Studies in Higher Education, 31(2), 219-233.

[6] Ferrell, G. (2013) Supporting Assessment and Feedback Practice with Technology: From Tinkering to Transformation. [Online]. Available from:

<http://jiscdesignstudio.pbworks.com/w/file/fetch/70107184/Jisc\%20AF\%20Final\%20Synthesis \%20Report\%20Oct\%202013\%20v2.pdf>.

[7] Biggs, J. B. \& Tang, C. (2011) Teaching for Quality Learning at University: What the Student Does. SRHE and Open University Press imprint. Maidenhead: McGraw-Hill [u.a.].

[8] Brown, S. A., Armstrong, S. \& Thompson, G. (1998) Motivating Students. London; Birmingham: Kogan Page; SEDA.

[9] Race, P. \& Staff and Educational Development Association (1993) Never Mind the Teaching Feel the Learning. Birmingham: SEDA.

[10] Feather, N.T. (Ed.) (1982) Expectations and Actions: Expectancy-Value Models in Psychology, LEA: Hillsdale, N.J.

[11] Jarvis, P., Holford, J., Griffin, C. (2003) The Theory \& Practice of Learning, 2nd ed. ed, Kogan Page: London; Sterling, VA.

[12] Biggs, J.B. (1987) Student Approaches to Learning and Studying, ACER research monograph, Australian Council for Educational Research: Melbourne. 